\title{
Global Dimension of the Security of the National Financial System of Russia
}

\author{
Ignatova T.V. \\ South-Russian Institute of Management - branch of Russian \\ Presidential Academy of National Economy and Public \\ Administration, \\ Rostov-on-Don, Russia, \\ tignatova@aaanet.ru
}

Evlakhova Yu. S.

Rostov State University of Economics,

Rostov-on-Don, Russia,

evlahova@yandex.ru

\author{
Dudukalov E.V. \\ South-Russian Institute of Management - branch of Russian \\ Presidential Academy of National Economy and Public \\ Administration, \\ Rostov-on-Don, Russia, \\ dudukalov@uriu.ranepa.ru
}

\author{
Alifanova E.N. \\ Rostov State University of Economics, \\ Rostov-on-Don, Russia, \\ alifanovaen@mail.ru
}

\author{
Aleksina I.S. \\ Yaroslav-the-Wise Novgorod State University, \\ Veliky Novgorod, Russia, \\ Irina.Aleksina@novgu.ru
}

\begin{abstract}
- the article is devoted to the need to revise the approaches to the organization of the financial system in the modern world. The authors considered an alternative in the form of a transition to widespread use of cryptocurrencies at the national level. It is shown that adjustments in public policy due to the spread of COVID-19 affect the rates of fiduciary currencies in the world. It was concluded that the volatility of cryptocurrencies is extremely high, but the rate movement corridor remains stable, and the forecast for the value of many digital currencies, in contrast to fiduciary ones, remains positive. The impact of the exchange rate dynamics on the financial security of countries is due to the fact that in the context of the likely development of a pandemic, entire countries or groups of countries may abandon isolated from the rest of the world for an indefinite period. On the exchange rate of national currencies, multidirectional forecasts are given, which create difficulties for investment and planning, even in the medium term. This will be perceived neutrally (or even positively) by the international community, as the situation in recent months has shown, and it is obvious that this instrument can work even better than economic sanctions. Countries - technology leaders will not be subject to isolation or sanctions, therefore, the article justifies the introduction of blockchain technologies and cryptocurrencies. As a result of the study, the authors determined that the protection of national interests is facilitated by the creation of their own payment system in digital currency, free from the influence of the conjuncture, sanctions and speculation. The results obtained can be used by banking organizations and state financial bodies in the development of financial security policy.
\end{abstract}

Keywords-financial system, financial security, cryptocurrency, blockchain, fiduciary currency

\section{INTRODUCTION}

The problems of the imperfection of the Bretton Woods system indicate possible ways of development of the global and national financial systems: the need to return to the "gold standard" or establish a new standard. At the same time, various options are offered, for example, the energy equivalent of the national currency, in which the exchange rate will depend on oil reserves, volumes of electricity generated and similar variables. With all the advantages of such an alternative for Russia, even in our country it is not being considered seriously at the present time, let alone Europe, which is energy-dependent and not interested in a scenario that will obviously undermine the stability of the Euro.

Cryptocurrency as an alternative is already finding its supporters everywhere. Already today, Switzerland allows its citizens to pay utility bills with cryptocurrencies, while the Monetary Authority of Singapore (MAS) has a blockchainbased interbank system. The UK Labor Department makes payments to retirees that are managed through a cryptocurrency-enabled mobile app.

The introduction of new technologies in Russia is hampered by international sanctions, for example, the US sanctions against Russia suggest that Russia does not gain access to certain technologies, but at the same time the technologies available in Russia are used by the United States, as, in particular, with the rocket engines RD-181 and RD-180.

An analysis should be made of why Russia, where the consequences of COVID-19 are not as pronounced as in the 
United States, is faced with the depreciation of its own currency, and the United States, despite the huge additional emission, ensures the stability of the national currency, incommensurate with the economic situation and the volume of external debt.

This is due to the fact that trading on stock exchanges is organized using automated algorithms that withdraw investors' funds from ruble assets when the first negative prerequisites appear, which will not necessarily develop further and lead to real problems in the national economy. It seems to us that it is possible to break this chain unilaterally only if there is a transition from the fiduciary (fiat) ruble to the digital ruble.

\section{RESEARCH METHODS AND MATERIALS}

The methodological basis of the study was the theory of global finance [1], financial crises [2], globalism, postindustrialism and technological determinism. The works devoted to the financial crises of the last three years in the cross-country context are also of considerable interest. Alexakis and Pappas underlined that "at the same time financial integration may facilitate the spread of financial instability across countries and markets, as has been the case during both the Global Financial Crisis (GFC) of 2007-2009 and the European Sovereign Debt Crisis (ESDC), with adverse impact on the relations amongst the member countries of the European Union (EU)" [3]. In the context of the 2020 pandemic, technologies ensured the functioning of the global economy of the economy as a whole and, in particular, made it possible to avoid the closure of organizations due to the threat of infection - ensured the continuous operation of financial, educational, scientific and other organizations in the context of COVID-19. There is no doubt that digital technologies today not only change the world, but in a certain sense and in certain situations even save it.

One of the most advanced technologies of today in the field of IT is blockchain, a new concept of the financial system for Russian scientific analysis. It is especially interesting that the interconnection of the blockchain with the global economy through the cryptocurrencies launched on its basis makes it unique for today.

Technology and finance have been closely intertwined throughout their history. The production of precious coins in the past, the printing of fiat money of today, electronic money in bank accounts, network money - all this is supported by the most modern technologies. Cryptocurrency is also in this row, as it is based on the most advanced distributed data storage technology today. Financial and technological elements organically are interrelated and act as one of the key factors in the development of the modern economy, dating the development of mankind to periods from one scientific and technological revolution to another, and the cycles of economic development from one technological structure to another.

At the same time, technologies have always lagged behind the development of economic relations - the needs of ensuring economic growth gave rise to new forms of relations, changing currency systems, reserve currencies and priority means of calculation. At the same time, regulation has never been adequate to new challenges. This happened once again with the cryptocurrency, the popularity of which and the growth of the rate are the answer to the challenge of the time. During 2017, Bitcoin grew in price by almost $2000 \%$ and at the peak of its popularity attracted widespread attention, not only in investor circles, but also among the general population. This gave rise to an active discussion about the possible regulation of operations with cryptocurrencies, which was based on the desire to impose new taxes on its owners.

In 2018, Bitcoin, as the flagship of the world of cryptocurrencies, has significantly lost in value, which also negatively affected the rates of other digital currencies launched in large quantities for various blockchain projects. After that, the rhetoric changed and the issue of protecting the interests of citizens from the consequences of speculative changes in cryptocurrency rates came to the fore.

The current attempts by national governments to express their attitude towards cryptocurrency through government regulation could determine the further development of these countries for the next decades. There are countries that create and maintain a favorable cryptoclimate (for example, Switzerland), but there are also those that advocate the most stringent regulation and even limitation of its circulation (for example, India, where until recently the position was sharply negative).

Russia observed a certain neutrality, but currently a bill is under consideration in the State Duma that actually prohibits the trade and use of cryptocurrencies on the territory of the Russian Federation and provides for administrative and even criminal liability for its violations. Its adoption means a ban on the organization, release and circulation of cryptocurrencies on the territory of the Russian Federation, the activities of any Russian cryptocurrency exchanges [4]. The cryptocurrency can only be purchased in foreign markets.

Financial relations are an integral element of economic relations and since financial relations are mediated by legal norms, in the context of the digitalization of the economic system, elements may arise that do not fit into the framework of existing regulation. Therefore, for the effective functioning of the financial system, their modification or elimination is necessary. In this regard, it is important to timely apply legal norms that allow changing the order of monetary relations. This is the only way to ensure the effective development of the digital economy.

It is known that in the BRICS format, attempts were made to agree on the creation of a single digital currency in order to use it as an alternative to the US dollar, but they did not receive proper development. And even on the contrary, in India, since April 2018, there has been a de facto ban on cryptocurrencies, it was proposed to deprive individuals of freedom for up to 10 years for mining, storing, selling, transferring and issuing cryptocurrency.

However, after 2 years, the directive of the Reserve Bank of India banning reporting entities from providing banking services to cryptocurrency companies was canceled. However, the country suffered serious damage as local exchanges and startups were forced to close or relocate to other countries. The country's reputation has also been undermined, but India's high-tech potential is good enough to catch up. Other BRICS countries should take this negative experience into account and not repeat such mistakes, since the consequences for them may be incomparably more dramatic. 


\section{RESULTS AND DISCUSSION}

The development of the digital economy meant ensuring unprecedented stability and minimizing the impact of the global environment on global economic development. This was to contribute to the eradication of extreme poverty, the accelerated provision of global prosperity and the development of social integration in the world. But the traditional criteria that measure the success of countries in building a digital economy turn out to be uninformative, since a digital economy based on a fiat currency cannot be fully effective. We see how in countries with a high level of digitalization, the dominance of the service sector and high formal indicators of the development of the digital economy, economic downturns can occur. Trust-based fiat money depreciated as quickly as issuing governments lost trust.

At its core, cryptocurrency is devoid of the shortcomings of fiat money that lead to crises: it is free from politics and borders, it cannot be printed unlimitedly, no intermediaries are required, there is no centralization. But in order to talk about cryptocurrency as an analogue of national currencies, it is necessary to form a full-fledged digital economy. Bitcoin is based on two fundamental cryptographic technologies: publicprivate cryptography of keys for trade and payment, firstly, and also cryptographic confirmation of transactions (transactions), secondly [5].

Today, the leaders in the development of the digital economy are the United States and China. In recent years, the influence of the Internet markets on the Russian economy has also been growing. By 2021, the contribution of the digital economy may reach $4.7 \%$ of GDP. Mobile technologies are developing especially actively. Accordingly, the segment of the mobile economy is growing, which, according to forecasts for 2021, may outstrip agriculture.

In Russia, the main factor in the development of the digital economy is the formation of an efficient payment infrastructure [6]. The experience of China and India shows that in the future, the creation of business ecosystems that unite trading platforms, unified payment centers and regulatory bodies will play a significant role [7]. The Russian digital economy should be based in its development on the interests of key international partners: the EAEU, SCO, BRICS. To ensure the stable development of the Russian economy and financial system, it is necessary to ensure the effectiveness of management in business structures in all sectors of the economy through the use of new digital platforms and technologies. In the public sector, the financial system should be aimed at the deepest application of digital technologies in the field of regulation of financial relations, the formation and use of the state budget for priority areas of the economy, the organization of financial supervision and control, and the establishment of standards for the digitalization of the economy on a regional basis.

It should be noted that financial management in Russia does not yet sufficiently use this sector in its activities. The formation of a digital economy will help optimize cash flows, improve the efficiency of using monetary resources and ratings of Russian corporations, and reduce financial risks when using financial instruments. For this, there are prerequisites, necessary sources of financing and conditions of activity. But the problem may arise with further regulation, which limits the possibility of blockchain development in
Russia. Boeme, Kristin and others determined block-chain as a process: "Every new transaction that is published to the Bitcoin network is periodically grouped together in a "block" of recent transactions. To make sure no unauthorized transactions have been inserted, the block itself is compared to the most recently published block-yielding a linked sequence of blocks, or "block chain" [5].

Today, digital currencies are prohibited as a means of payment in Russia. The idea of regulating the crypto market does not promote business development or Russia's interaction with the global economy on a digital level. The above legislative initiatives will lead to the decline of the IT industry and another "brain drain" to the west. This is due to the fact that one of the main global trends is the cryptoization of the IT industry. Due to the restrictions imposed in Russia, it will be impossible to create an up-to-date and popular crypto product.

Government distrust of digital tokens could set the country back in its digital development. In Russia, unlike the countries named above, it is wary of all cryptocurrencies, and innovation is mainly stimulated by startups, not by the state. At the same time, it does not take into account the fact that in the modern world there is intense competition for intellectual capital. In 2017, Russia ranked 81st among 118 countries in the talent competitiveness ranking. In July of the same year, the program "Digital Economy of the Russian Federation" was adopted, which gave a start to the development of a digital society and the formation of a model for the transition to a digital economy. However, there are now a number of factors that threaten its implementation:

1. Budgetary spending on education in Russia is growing every year. However, the growth rate is not comparable with the level of China, the USA, and Western Europe. So, if in Russia up to $1 \%$ of GDP is spent on education, then in China $4 \%$, and in developed countries $-5-7 \%$. It is no secret that the success of any developed economy is based on a strong and well-funded education system.

2. In Russia, R\&D spending is less than $1 \%$ of GDP, in European countries - 2\%, in China $-2.2 \%$.

3. Innovative enterprises need strong support, both in the financial sector and in the political environment. One of the most important conditions for the development of innovation and innovative technologies is the promotion of an entrepreneurial climate. In Russia, high rates on credit products for small businesses restrict access to capital and hinder the movement towards new inventions [8]. Therefore, it is the state that needs to intensify the inflow of direct and venture investments into business.

4. Stimulating innovation by improving tax instruments. Russian tax policy exempts R\&D enterprises from VAT. For example, in China, the tax policy in this direction is also liberal. But the criteria for selecting an enterprise are much stricter. Thus, exactly the desired effect from state support is achieved - it is obtained on a competitive basis based on an analysis of real results, which increases its value. And the fact that more than $30 \%$ of startups that launched their own blockchain-based projects did not even try to implement the projects presented to investors for which they received funding indicates the need for a lot of work in selecting recipients of state support.

5. The national payment system "Mir" and the system for 
transferring financial messages (STFM) of the Bank of Russia do not solve their problems at the international level. Financial globalization has spread widely in the form of digital financial technology. In times of globalization of the economy, the processes of integrating the markets of various countries on the path of capital movement are becoming more active, as well as barriers to the use of digital financial technologies in settlements, transmission and storage of data are being reduced. Russia remains technologically dependent even in operations with fiat currencies.

Increasing competition in world markets, expanding borders and entrenching globalization create a need for clearly coordinated, structured and systematic actions of states to ensure their financial stability. In the long term, the key role will be played by the globally developing financial market, in which digital technologies are increasingly used to conduct transactions. Naturally, appropriate specialists and institutions are needed to manage the processes that are associated with the digital economy.

\section{CONCLUSIONS}

The issues of financial stability in the current conditions are especially relevant, since globalization and the digital economy not only open up new opportunities, but also pose serious threats: the constant growth of competition, the complication of economic and political problems, and the lack of specialists in the field of digital finance. At the same time, any negative changes occurring with fiat money reduce the stability of the country's financial system, cause inflation to rise and the purchasing power of the population to fall. As a result, the achievements of digitalization are depreciating, and efforts to modernize the economy do not give the desired effect. In fact, this applies to each country, and the fact that the countries of the main reserve currencies demonstrate relative economic stability and stability of exchange rates does not mean that this is due to the operation of objective economic laws. We dare to suggest that to a large extent this is behind the consensus of the interested forces, especially in the context of the growing danger of financial crises [9].

This conclusion can be drawn from the totality of many empirical observations and the most significant circumstance is that the development of the real economy lags behind the financial system in many developed countries. In some countries, total financial assets exceed GDP. So, in 2000, in comparison with 1980, the assets of financial institutions grew in Great Britain from $100 \%$ of GDP to $300 \%$, in Germany from $200 \%$ to $350 \%$, in the USA - from $111 \%$ to $250 \%$.

This circumstance is key, but not the only one. Against the background of the growing interdependence of economies and the increasing complexity of the global economic system, financial stability is disrupted and the cryptocurrency can both increase this instability and reduce it. To prevent crisis situations in the national economy, a thoroughly worked out financial security strategy is needed, but it should not be based on closing real or virtual borders, isolation from modern technologies, ignoring objective laws and trends.

Ignoring the cryptocurrency in this case and limiting its turnover will lead to the fact that in the countries that have taken this path, uncertainty will increase [10]. At the same time, the launch of its own blockchain projects and national cryptocurrencies will ensure the strengthening of national economies, exclude devaluation and abandon the dollar standard. That is why large corporations and governments around the world are already translating individual settlements into a cryptocurrency format.

In Russia, when deciding on the regulation of the turnover of cryptocurrencies, it is necessary to take into account that the adoption of regulations restricting their use, instead of launching its own cryptocurrency supported by the ruble, creates a threat to lose another competitive niche and lag behind in the use of modern technologies, as has already happened several times before. and will also weaken the country's position in the freedom to do business index. The ban on the creation of Russian stock exchanges and the trading of digital currencies within the country will contribute to the emergence of new shadow schemes and lead to a new wave of staff drain abroad.

\section{Acknowledgments}

The reported study was funded by RFBR according to the research project No. 18-010-00657.

\section{References}

[1] X. Jin, and X. An, "Global financial crisis and emerging stock marke contagion: A volatility impulse response function approach", Research in International Business and Finance, 2016, vol. 36, pp. 179-195. DOI:10.1016/j.ribaf.2015.09.019

[2] S. Aboura, and J. Chevallier, "Volatility returns with vengeance: Financial markets vs. commodities", Research in International Business and Finance, 2014, vol. 33, pp. 334-354 DOI:10.1016/j.ribaf.2014.04.003

[3] Ch. Alexakis, and V. Pappas, "Sectoral dynamics of financial contangion in Europe - The cases of recent crises episodes", Economic Modelling, 2018, vol. 73, pp. 222-239. DOI: doi.org/101016/j.econmod.2018.03.018

[4] Ch. Alexakis, T. Ignatova, and A. Polyanin, "Tests for sectorial market efficiency of the dynamics in Moscow Exchange", Revista ESPACIOS, 2019, vol. 40(10), p 17. Retrieved from http://www.revistaespacios.com/a19v40n10/19401017.html

[5] R. Bohme, N. Christin, B. Edelman, and T. Moore, "Bitcoin Economics, Technology, and Governance", Journal of Economic Perspectives, 2015, vol. 29(2), pp. 213-238. DOI: 10.1257/jep.29.2.213

[6] M. Konyagina, Digital economy of Russia: traditional problems of development. In: Architecture of finance: new solutions under conditions of digital economy: conference proceedings, SPb, Publ.house of SPbGEU, 2019. (In Russ.).

[7] S. Song, "The Rise and Fall of Bitcoin in China: Central Bank Shuts Down All Chinese Bitcoin Exchanges", International Business Times, 2014, March 27.

[8] T. Ignatova, E.Platonova, A. Pavlyukova, and G. Sroslak, "Development of Sharing Economy in the Context of Digitalization of Joint Consumption", Advances in Economics, Business and Management Research, 2020, vol. 139, pp. 359-362. DOI: doi.org/102991/aebmr.k.200509063

[9] D.Dimitriou, D. Kenourgios, and T. Simos, "Financial crises, exchange rate linkages and uncovered interest parity: Evidence from G7 markets", Economic modeling, 2017, vol. 66, pp. 112-120. 2017. DOI:10.1016/j.econmod.2017.06.003

[10] E. Ittay, and E. Sirer, Majority is Not Enough: Bitcoin Mining is Vulnerable. In Financial Cryptography and Data Security, vol. 8437 of Lecture Notes in Computer Science, Luxembourg: Springer, 2014 